\title{
Proteção social e trabalho do assistente social: tendências e disputas na conjuntura de crise mundial*
}

\author{
Social protection and the social worker's work: \\ tendencies and disputes in the worldwide crisis scenario
}

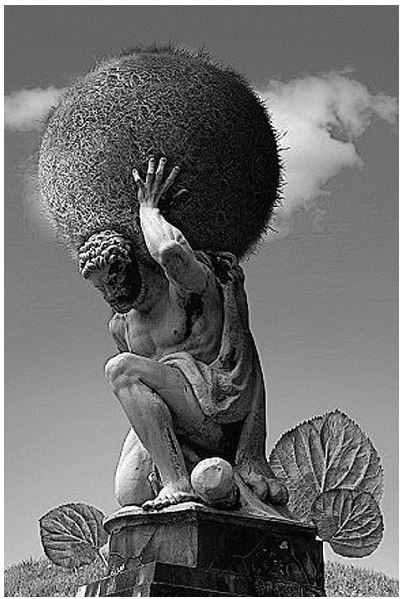

Raquel Raichelis**

Resumo: Este texto trata das transformações que atingem as políticas de proteção social no contexto da crise capitalista contemporânea e seus desdobramentos no trabalho do assistente social. Problematiza o trabalho do assistente social evidenciando por inteiro sua condição como trabalhador assalariado que vende sua força de trabalho em troca de um salário. $\mathrm{O}$ texto também analisa os constrangimentos a que eles se veem submetidos diante dos processos de intensificação e precarização do seu trabalho nos espaços institucionais públicos e privados onde exercem atividades de elaboração, gestão e execução de programas e serviços sociais.

Palavras-chave: Crise mundial. Políticas de proteção social. Intensificação. Precarização. Assistente social. Trabalho assalariado.

Abstract: This article deals with transformations affecting social protection policies in the context of contemporary capitalist crisis and its developments in the field of social work. At the same time, it

* O presente artigo é uma versão ampliada da exposição apresentada em mesa redonda no VI Seminário Anual de Serviço Social: A "proteção social" diante da destrutividade do capitalismo — significado e crítica, promovido pela Cortez Editora em 13 de maio de 2013 no Tuca, auditório da PUC-SP. Ao mesmo tempo expressa reflexões decorrentes dos estudos realizados durante o pós-doutorado na Universidade Autônoma de Barcelona (UAB), sob a supervisão do prof. dr. José Adelantado Gimeno, a quem agradeço pela atenciosa receptividade durante minha estadia.

** Doutora em Serviço Social, professora do Programa de Estudos Pós-Graduados em Serviço Social e coordenadora do Núcleo de Estudos e Pesquisas sobre Trabalho e Profissão da PUC-SP/São Paulo, Brasil. Pesquisadora produtividade do CNPQ e bolsista da Capes de pós-doutorado na Universidade Autônoma de Barcelona, no Grupo de Investigación Globalización, Educación y Políticas Sociales (GEPS), do Departamento de Sociologia.E-mail: raichelis@uol.com.br. 
discusses the social workers' work revealing their condition as workers that sell their work force in exchange of a salary. The article also addresses the constraints they face because of the processes of intensification and precariousness of their work in the public and private spaces where they develop activities of elaboration, management and execution of social programs and services.

Keywords: Worldwide crisis. Social protection policies. Intensification. Precariousness. Social worker. Salaried work.

\section{Introdução}

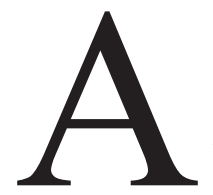

crise que se inicia nos anos de 1970 indicando os primeiros sinais de esgotamento da fase expansiva do desenvolvimento capitalista no pós-Segunda Guerra Mundial, é responsável direta pelas transformações do Estado e reconfiguração das políticas sociais nas décadas seguintes. São dinâmicas que envolvem a questão social e, portanto, remetem às contradições geradas pelas relações entre as classes sociais, em um complexo de novas determinações que vão ensejar repostas do Estado e do capital à crise de acumulação.

Este movimento evidencia que as crises no capitalismo não são fenômenos eventuais, mas processos imanentes que se manifestam ciclicamente em função da tendência de queda da taxa de lucros provocada pela concorrência intercapitalista, aumento da produtividade do trabalho e sobreacumulação de capital, em contextos de baixos salários e desemprego crescente.

Para Mészáros (2009) e outros analistas, esta é uma crise estrutural, expansionista, destrutiva e, no limite, incontrolável. E quanto mais aumentam a competitividade e concorrência intercapitais, mais nefastas são suas consequências, das quais se destacam: a destruição e/ou precarização da força humana que trabalha e a degradação crescente do meio ambiente, na relação metabólica entre homem, tecnologia e natureza, subordinadas aos parâmetros do capital e do sistema produtor de mercadorias.

Cabe salientar que esse processo de reorganização do capitalismo, para fazer frente a mais uma de suas crises estruturais, só se viabiliza pela intervenção ativa dos Estados nacionais e o papel do fundo público como financiador da acumulação.

Simultânea e dialeticamente, as políticas sociais representam a face de luta dos movimentos sociais e a dimensão de conquista da classe trabalhadora decor- 
rente das pressões e mobilizações em busca de respostas a necessidades sociais de reprodução social, ainda que invariavelmente de modo insuficiente e limitado.

Nesses termos, é preciso romper com qualquer linearidade na análise das políticas sociais e dos espaços ocupacionais nos quais se inserem os assistentes sociais e demais trabalhadores sociais, considerando as formas de enfrentamento do capital às suas crises de acumulação, que aprofundam e agravam as expressões da questão social, mas também desencadeiam respostas da sociedade e da classe trabalhadora em seu movimento de resistência e defesa de direitos conquistados historicamente.

Nesse cenário, o trabalho do assistente social sofre profundas inflexões decorrentes das novas configurações do mercado de trabalho que incidem também nos espaços em que os assistentes sociais se inserem como trabalhadores assalariados, que não escapam das determinações estruturais que movem os processos de intensificação e precarização do trabalho, no contexto da crise mundial.

\section{Crise do capital, reconfiguração do Estado e das políticas sociais: o rumo das mudanças}

O pressuposto desta reflexão é que as transformações estruturais decorrentes da nova etapa da financeirização do capital atravessam diferentes dimensões da vida social, incidem nas relações e formas de gestão do trabalho, nos modos de expressão das sociabilidades individuais e coletivas, imprimem novas racionalidades às formas de organização do Estado, das políticas públicas e dos sistemas de proteção social, alterando os critérios de distribuição do fundo público e, em consequência, modelando as formas de organização e prestação dos serviços sociais públicos.

Para analisar as transformações societárias contemporâneas partimos de uma formulação-chave de Iamamoto (2007), para quem processos societários que são tratados com frequência como dinâmicas independentes, na realidade compõem uma totalidade que precisa ser considerada em suas conexões e determinações.

Nas palavras da autora:

a mundialização financeira sob suas distintas vias de efetivação unifica, dentro de um mesmo movimento, processos que vêm sendo tratados pelos intelectuais (e acrescen- 
to, também pelos assistentes sociais) como se fossem isolados ou autônomos: a "reforma" do Estado, tida como específica da arena política: a reestruturação produtiva, referente às atividades econômicas empresariais e à esfera do trabalho: a questão social, reduzida aos chamados processos de exclusão e integração social, geralmente circunscrita a dilemas da eficácia da gestão social; à ideologia neoliberal e concepções pós-modernas, atinentes à esfera da cultura. (Iamamoto, 2007, p. 114; grifos da autora)

Agora o capital financeirizado passa a comandar a totalidade do processo de acumulação por meio da integração das grandes empresas industriais com as instituições financeiras, como bancos, fundos de investimento, fundos de pensão, seguradoras etc., num movimento permanente de valorização e busca de lucros, encobrindo a ampliação das relações de exploração do capital sobre o trabalho, criando a mística do "dinheiro que gera dinheiro" e impondo novas formas de dominação à classe trabalhadora (Iamamoto, 2007).

A dinâmica de mundialização e financeirização da economia e dos mercados insere-se num amplo movimento de reconfiguração do capitalismo, ancorado pela grande indústria transnacional em estreita associação com o mundo das finanças e com os interesses do capital rentista.

Nos termos de Iamamoto (2007, p. 107): “O capital financeiro assume o comando do processo de acumulação e, mediante inéditos processos sociais, envolve a economia e a sociedade, a política e a cultura, vincando profundamente as formas de sociabilidade e o jogo de forças sociais".

Contudo, sabe-se que a esfera das finanças não tem o poder de criar valores em si mesmos, pois ela se alimenta da riqueza criada pelo investimento produtivo, embora a aparência seja de que o "dinheiro cria mais dinheiro" no circuito fechado dos mercados financeiros, como se fossem instâncias autônomas em relação às classes sociais e ao Estado (Iamamoto, 2007).

Para que essa dinâmica seja garantida, torna-se central a intervenção ativa dos Estados nacionais que, por meio do fundo público financia a acumulação e as altas taxas de lucratividade do capital em detrimento do trabalho.

A intervenção estatal no processo de reprodução do capital ocorre na própria gestão da mercadoria força de trabalho. Para os funcionários do capital (capitalistas), a força de trabalho se constitui em custo e, por conseguinte, a intervenção estatal, em termos de educação, preparação da mão de obra etc. vem no sentido de minimizar ao máximo 
esse custo para o proprietário do capital. A utilização capitalista da força de trabalho implica em dois aspectos distintos e complementares: disciplina do trabalho e insegurança no emprego. (Lima, 2010, p. 72)

Como bem analisou Netto (2009, p. 26), o Estado no capitalismo monopolista atua como um instrumento de organização da economia, operando como um administrador dos ciclos de crise, o que não ocorre sem contradições entre os diferentes interesses em luta. É por meio da política social que o Estado busca administrar as expressões da questão social, de modo a atender demandas de várias ordens, inclusive dos trabalhadores, para assegurar condições necessárias ao desenvolvimento monopolista do capital.

A mundialização financeira em curso faz com que essas dinâmicas atravessem fronteiras e continentes, reconfigurando os estados sociais, tanto nos países centrais quanto na periferia do sistema, com impactos diferenciados mediados pelas realidades particulares de cada país e de sua formação social e econômica.

Esta tendência mundial fez com que Ulrich Beck, em recente artigo no jornal espanhol El País (2012), ao falar da crise da social democracia europeia e da adoção de políticas neoliberais de desregulamentação e flexibilização das relações trabalhistas, afirmasse que "a consequência não desejada da utopia neoliberal é uma brasilização do Ocidente". Para ele são notáveis as similitudes de como se estão conformando o trabalho remunerado no chamado Primeiro Mundo e como é o do Terceiro Mundo. A temporalidade e a fragilidade laborais, a descontinuidade e a informalidade estão alcançando as sociedades ocidentais até agora baluartes do pleno emprego e do Estado de Bem-estar".

Em seu livro A política do precariado, Ruy Braga (2012) dialoga com esse tipo de análise e questiona se a crise que se agrava hoje na Europa seria mais um indício de "brasilianização", como alguns analistas, entre eles Ulrich Beck, vêm se referindo à crise que afeta hoje os países capitalistas centrais.

Ou simplesmente, como defende Braga, a demonstração de que o desenvolvimento capitalista, além de permeável a uma multiplicidade de ritmos e deslocalizações, não é dirigido por nenhum telos progressista, revelando-se, ao contrário, desigual e combinado, numa leitura dialética do desenvolvimento histórico do capitalismo" (2012, p. 19).

Segundo Braga (2012), com quem concordamos, não se trata de brasilização ou brasilianização dos países capitalistas centrais, mas sim da expressão de mais 
uma crise econômico-social do capital global para conviver com crises cíclicas, mesmo que a atual tenha traços de uma crise estrutural sem precedentes e de largas proporções, assumindo cada vez mais a forma endêmica, crônica e permanente.

Este contexto econômico mundial e a adoção das políticas neoliberais de desregulamentação e flexibilização do trabalho e dos direitos trabalhistas e sociais afetaram profundamente o campo das políticas sociais, e embora haja um amplo debate acerca da profundidade e da intensidade de seus efeitos, vários autores referem-se à combinação de mudanças quantitativas e qualitativas que, desde finais de 1970, atingem os diferentes regimes de bem-estar social europeus e norte-americano.

Embora não se trate de falência ou extinção do Estado de Bem-estar (EB), como muitos analistas, de forma apressada ou ideologicamente comprometida, têm afirmado, são intensos os processos de reconfiguração, reestruturação ou recalibragem política, institucional e ideológica que atingem os EB (termos que variam segundo os autores de referência).

Os resultados das pesquisas de inúmeros analistas europeus (Clayton e Pontusson, 1998, Pierson, 2001, Antón, 2009, Moreno, 2012), apontam tanto mudanças quantitativas, com corte nos gastos sociais e redução da intensidade protetora do Estado, quanto mudanças qualitativas na direção da remercantilização de bens e serviços, com adoção de políticas chamadas "ativas", por estimularem a "integração" no mercado de trabalho, em oposição às assim denominadas políticas "passivas" do EB, que supostamente gerariam acomodação dos trabalhadores e cujo exemplo emblemático é o seguro-desemprego (Adelantado, 2012).

José Adelantado, pesquisador das transformções do EB na Espanha e na União Europeia (UE), aponta que esses países, com diferenciações internas, estão experimentando uma mudança paradigmática: de um Estado de Bem-estar Protetor (EBP), que protegia o cidadão "desde o berço até o túmulo" (from cradle to grave), para um Estado de Bem-estar Inversor (EBI), que pretende converter o gasto em proteção social em uma "inversão aos cidadãos para que eles se protejam a si mesmos frente ao mercado, com base na ativação de suas capacidades e apelos à responsabilidade pessoal frente aos riscos" (Adelantado, 2012, p. 2; tradução da autora).

Vários autores (apud Adelantado, 2012) vêm analisando essa dinâmica dos Estados de Bem-estar, adotando diferentes denominações: Estado Social Ativo (Vielle, Pochet e Cassiers, 2005); Estado Possibilitador (Taylor-Gooby, 2008); Estado Schumpeteriano (Jessop, 1994); Estado de Bem-estar Inversor (Morel, 
Palme e Palier, 2012), todos convergindo na identificação das transformações em curso rumo à redução da intensidade protetora do Estado e retração de direitos, ressaltando contudo a importância de acompanhar as expressões desse processo nas distintas realidades nacionais e regionais.

Para Noguera (2000), analisando as mudanças no Estado de Bem-estar espanhol e tomando como base os três modelos de Bem-Estar social formulados por Esping-Andersen (1991), a Espanha se configura como um híbrido que incorporou elementos típicos dos três modelos em suas diferentes fases de transição democrática, e hoje estaria apresentando uma ênfase no terceiro tipo, o assistencial-liberal, configurando-se um "modelo específico de bem-estar 'latino-mediterrâneo"” (p. 477; tradução da autora).

Há consenso entre os analistas de que mesmo as políticas universais de educação e saúde na Espanha e demais países da UE têm sido permanentemente ameaçadas por tendências privatizantes na provisão de serviços sociais, que é objeto de endurecimento dos testes de meios (means testing) para garantir o acesso e a permanência em prestações não contributivas, programas de renda mínima de inserção, subsídios de desemprego, ajuda familiar não contributiva etc. Paralelamente, incrementou-se o caráter seletivo e dualizador de alguns programas que não respondiam ao "modelo assistencial", como a formação laboral, a política familiar, de imigração ou a política do mercado de trabalho.

Segundo a reflexão de Noguera (2000, p. 478; tradução da autora), mais do que uma assistencialização observa-se uma dualização do bem-estar público: "surge com visibilidade crescente uma linha divisória entre os 'integrados' no emprego e, por isso, nos regimes contributivos, com uma proteção social pública 'forte' ou com planos de previdência privados, e os 'não integrados' ou precarizados, com uma proteção social pública 'fraca' ou simplesmente sem nenhuma proteção".

É possível identificar nesse contexto clara regressão da universalidade de direitos e do padrão alcançado pelo bem-estar nos países centrais, mesmo considerando a heterogeneidade dos modelos implantados. No caso da Espanha, é curiosa a semelhança com a realidade brasileira no que se refere ao sistema de seguridade social, que antes mesmo de ser completamente operacionalizado já vem sofrendo erosão dos princípios consagrados na Constituição federal de 1988. Para o caso da Espanha, Noguera (2000) usa uma metáfora para afirmar que se encontram na curiosa situação de quem, antes de ter concluído o teto da casa, começam a se deparar com a perfuração da base e erosão das vigas da edificação. 
Reconhecendo, portanto, as multidimensionalidades da crise atual, as reformas neoliberais em curso e a disputa de projetos entre as diferentes coalizões de atores e organizações, o que se observa é que a maioria dos países está se movendo na direção da social liberalização do sistema de proteção social: workfare na França, modelo anglo-saxão na Alemanha, dualização do bem-estar e da proteção social nos países mediterrâneos, aumento da desigualdade de renda nos países nórdicos, reformas liberais em curso na Grã-Bretanha etc.

Essa nova geração de políticas sociais expressa as transformações do Welfare no contexto de crise e reconfiguração deste modo de regulação social-democrata que sustentou os Estados de Bem-estar Social nos "trinta anos de ouro" do capitalismo; e, ao mesmo tempo, indica a transição para um novo modelo de regulação estatal - o workfare - núcleo estruturante do novo padrão de políticas sociais, que busca consolidar nova racionalidade redistributiva, fundada no compromisso obrigatório dos cidadãos de se subordinarem a medidas de "ativação" (políticas ativas de emprego) para a inserção e a integração no mercado de trabalho, como contrapartida do acesso à "proteção social".

No entanto, concordando com Lavinas (2013), cabe salientar que a finalidade do workfare não tem nada de civilizatória nem de preservação dos valores morais do trabalho, como quer fazer crer o pensamento conservador. Ao contrário, pauta-se em um novo padrão produtivo amplamente desfavorável aos trabalhadores, que torna compulsório aceitar qualquer emprego, ainda que indigno, mal remunerado e precário, em troca do direito à sobrevivência.

Resguardadas as particularidades das formações econômicas e sociais e de realização do capitalismo nos países europeus, inclusive com grande heterogeneidade entre eles, muitas destas tendências regressivas da proteção social se reproduzem também no Brasil, com enormes impactos para a classe trabalhadora e para o trabalho do assistente social.

\section{Expressões da crise no Brasil: impactos no trabalho e na proteção social}

No Brasil, antes mesmo da onda (neo)liberalizante dos ajustamentos estruturais, as diferentes formas de precarização do trabalho, os altos índices de subemprego e a informalidade da força de trabalho urbana e rural, bem como a ausência e a fragilidade do sistema de proteção social já se apresentavam como traços mar- 
cantes do capitalismo dependente brasileiro, na transição do trabalho escravo para o trabalho livre, contexto que desencadeia a questão social no país.

O chamado fordismo à brasileira guarda importantes singularidades em relação ao fordismo "clássico", caracterizando-se por um regime de trabalho com fraca proteção social e elevados índices de rotatividade da força de trabalho, derivados da informalidade e da precariedade estruturais do mercado de trabalho no Brasil.

Mais precisamente, em nosso país constituiu-se o que Braga (2012, p. 21) identificou como fordismo periférico, um sistema social estruturado pela combinação de economias e nações capitalistas desenvolvidas e subdesenvolvidas, dominado pela mundialização das trocas mercantis, constituindo-se em uma das principais mediações históricas entre os países capitalistas avançados e os países capitalistas subdesenvolvidos ou dependentes.

Se consideramos que é próprio do capitalismo, mesmo nos países hegemônicos, criar uma população excedente em relação às necessidades de reprodução do modo de produção, gerando desemprego e trabalho precário, no fordismo periférico essa sempre foi a regra.

Ao contrário do que aconteceu historicamente com o capitalismo nos países centrais, o Estado brasileiro não criou condições para a reprodução social da totalidade da força de trabalho, nem estendeu direitos de cidadania ao conjunto da classe trabalhadora, excluindo imensas parcelas de trabalhadores do acesso ao trabalho protegido e às condições de reprodução social.

Portanto, no caso do Brasil, onde a precarização do trabalho não é um fenômeno novo, as diferentes formas de precarização do trabalho e do emprego assumem na atualidade novas proporções e manifestações, que vêm sendo amplamente analisadas pela vasta produção sobre o tema em diferentes áreas e atividades econômicas.

A implementação, desde meados da década de 1990, do ideário neoliberal preconizado pelo Consenso de Washington e largamente difundido pelos organismos internacionais e multilaterais, de medidas de flexibilização do trabalho e desregulamentação de direitos só agravaram a situação já precária do trabalho e do emprego no país, provocando importantes reconfigurações nas relações de trabalho, nos direitos e na proteção social.

As transformações que o mundo do trabalho vem experimentando nas últimas décadas caracterizam uma nova era de precarização estrutural do trabalho (Antunes, 
2013; Alves, 2013), que incide tanto nas condições de uso da força de trabalho como em suas formas de contratação e gestão, diante das novas exigências de flexibilização e redução dos custos de reprodução da força de trabalho.

A denominada nova morfologia do trabalho (Antunes, 2005) desencadeia mudanças profundas nas formas de organização e relações do trabalho, gerando processos continuados de informalização, insegurança e desproteção no trabalho, e novas formas de contratação da força de trabalho assalariada por meio de trabalhos terceirizados, subcontratados, temporários, domésticos, em tempo parcial ou por projeto, além das formas regressivas que se supunha eliminadas, como o trabalho escravo, o trabalho infantil, para citar apenas algumas das expressões da precarização a que estão submetidos os trabalhadores no mundo do trabalho.

Por isso, para Druck (2009, p. 3), estamos presenciando um "novo" tipo de precarização social do trabalho que atinge a todos indiscriminadamente, embora com graus e intensidade distintos, mas cuja unidade é dada pelo caráter permanente e não mais provisório desta condição. É um processo que mina as formas de resistência e luta dos trabalhadores, disseminando a (falsa) ideia de fatalidade econômica e irreversibilidade política da situação presente.

O pressuposto integrador exercido pelo trabalho fordista vai perdendo força, mesmo naqueles países que não constituíram propriamente uma sociedade salarial (Castel, 1998), como é o caso do Brasil. A etapa atual de financeirização capitalista faz com que o trabalho, mediação fundamental das relações sociais e elemento estruturante da sociabilidade humana, seja destituído de sua função protetora para amplos segmentos da classe trabalhadora, cujos salários têm perdido potência integradora face à perda de direitos e benefícios dele derivados, o que repõe os termos do debate sobre a proteção social como direito universal e desmercadorizável.

O Estado passa à defesa de alternativas que envolvem a família, as organizações sociais e a "rede filantrópica de solidariedade social", abdicando de políticas universais ancoradas no direito de cidadania. As medidas postas em prática são reducionistas, voltadas primordialmente para situações extremas, com alto grau de seletividade e focalização, direcionadas à miséria e à pobreza absoluta, que não impactam de forma significativa os níveis de desigualdade social persistentes em nosso país.

Nesse contexto, as políticas de proteção social têm sido cada vez mais intensamente demandadas por coletivos de trabalhadores que, mesmo exercendo atividades remuneradas, têm suas relações de trabalho marcadas pela informalidade, baixos salários, precarização, desemprego intermitente, o que transforma e redefine o perfil dos usuários das políticas sociais e dos programas sociais ofertados. 
Crescem em várias partes do mundo os Programas de Transferência de Renda (PTR) enquanto estratégias de "alívio" da pobreza, sob o estímulo das agências internacionais e multilaterais. No Brasil, o Programa Bolsa Família (PBF), que tem seu foco na extrema pobreza, acabou por se destacar como núcleo central e face mais visível da política social brasileira na atualidade, inclusive pela magnitude de seu alcance, atingindo 13 milhões de famílias ou cerca de 50 milhões de pessoas (com previsão para mais de 17 milhões de famílias ou cerca de 68 milhões de pessoas em 2013).

O Programa Bolsa Família, apesar de representar importante via de acesso a benefícios não contributivos para parcela significativa da população, e de produzir impactos imediatos positivos na vida de seus beneficiários e na dinâmica das economias locais, principalmente de pequenos e médios municípios do NE e das zonas rurais, caracteriza-se pela sua ultrafocalização na extrema pobreza, operando com condicionalidades acompanhadas da adoção de práticas disciplinarizadoras e exigências de contrapartidas que constrangem as famílias beneficiárias a buscar as chamadas "portas de saída" na perspectiva da empregabilidade e do assim chamado empreendedorismo.

Aqui também a ideologia do workfare propaga-se rapidamente, endurecendo contrapartidas e critérios de elegibilidade (means testing), exercendo pressão para que os beneficiários da assistência social pública considerados "aptos ao trabalho" ingressem no mercado a qualquer custo, mesmo que seja para "estabilizar os instáveis" na precariedade laboral e nos baixos salários.

Diante desse cenário, as políticas sociais brasileiras, em especial a Seguridade Social, enfrentam profundos paradoxos. Pois se de um lado contam com as garantias constitucionais que pressionam o Estado para o reconhecimento de direitos, por outro se inserem nesse contexto de ajuste às configurações da ordem capitalista internacional, com seu caráter regressivo e conservador, que focaliza, ameaça o direito e a cidadania, trazendo de volta a meritocracia, a disciplinarização, a refilantropização, a criminalização da questão social.

\section{Intensificação do trabalho no campo dos serviços: notas para o debate}

A dinâmica societária desencadeada pela crise contemporânea, que vimos analisando, atinge a totalidade dos processos produtivos e também dos serviços, 
alterando perfis profissionais e espaços de trabalho das diferentes profissões, que, como o Serviço Social, têm na prestação de serviços sociais seu campo de intervenção privilegiado, e nas instituições sociais públicas e privadas seu espaço ocupacional por excelência.

Se o Serviço Social foi regulamentado historicamente como profissão liberal, seu exercício profissional se realiza mediatizado por instituições públicas e privadas, tensionado pelas contradições que atravessam as classes sociais na sociedade do capital e o assistente social submetido à condição de trabalhador assalariado, cuja atividade se assenta em normas próprias que orientam as relações de trabalho.

Portanto, ainda que o Serviço Social tenha seu estatuto de profissão liberal reconhecido, o trabalho do assistente social é tensionado pela relação de compra e venda da sua força de trabalho especializada. A condição de trabalhador assalariado - seja nas instituições públicas ou nos espaços empresariais ou "sem fins lucrativos", faz com que os profissionais não disponham totalmente, nem tenham controle sobre as condições e os meios de trabalho postos à sua disposição no espaço institucional.

Por outro lado, os processos de reestruturação produtiva, típicos das empresas capitalistas, penetram também a organização social do trabalho na esfera estatal, maior empregador da força de trabalho profissional, reestruturando e moldando a ação pública no campo das políticas sociais e dos serviços sociais. São processos que atingem o mercado de trabalho do assistente social produzindo tanto reduções como ampliações de espaços e postos de trabalho nos âmbitos estatais e privados, seja pelo alargamento das esferas de ação estatal, com maior ênfase no nível municipal, seja pela multiplicação das organizações sociais privadas e ONGs na atual conjuntura.

Este contexto é impulsionado também pela grande expansão do setor de serviços como uma importante característica do capitalismo monopolista. Para Braverman (1981), o crescimento do setor de serviços se deve à penetração do capital nos diversos setores da vida, transformando antigas formas de cooperação mútua, social, familiar e comunitária em atividades comercializáveis no mercado, especialmente a partir do capitalismo monopolista.

O alargamento do setor de serviços, típico do capitalismo monopolista, se vê reconfigurado pela dinâmica da reestruturação produtiva em curso desde a década de 1970, e particularmente pela incorporação da ciência e da inovação tecnológica e digital aos processos de produção e gestão do capital. 
Para Antunes (2008, p. 178), o que se pode observar no atual mundo do trabalho é uma maior inter-relação e interpenetração entre as atividades produtivas e improdutivas, as que ocorrem na fábrica e nos serviços, entre as atividades laborativas e as de concepção, que se expandem no processo de reestruturação produtiva do capital.

A expansão do trabalho em serviços, em esferas não diretamente produtivas, mas que muitas vezes desempenham atividades imbricadas com o trabalho produtivo mostra-se como outra característica importante da noção ampliada de trabalho, quando se quer compreender o seu significado no mundo contemporâneo. (Antunes, 2008, p. 177, grifos do autor)

Nesses termos, o trabalho em serviço, no contexto atual de desenvolvimento capitalista, não se autonomiza do trabalho em geral desenvolvido por trabalhadores assalariados, ainda que com particularidades de um tipo especializado de atividade realizado por agentes qualificados em nível superior e no âmbito estatal.

Os serviços, campo por excelência onde se situa a ação profissional do assistente social, são um tipo de trabalho em processo, nos termos de Meirelles (2006, p. 134), cuja atividade não se separa do seu executor, pois mais do que um produto trata-se do resultado da ação.

Ao mesmo tempo, cabe destacar as particularidades do trabalho em serviços pelo caráter relacional e interativo entre profissional e usuário, que implica atributos humanos para sua realização e a possibilidade de não ser totalmente capturado pelos dilemas do trabalho assalariado (Schutz e Mioto, 2012, p. 95), o que traz à reflexão as margens de autonomia relativa de que dispõem o profissional, considerando a ótica do trabalho coletivo e a direção política que o orienta.

O estudo de Dal Rosso (2008) sobre a intensificação do trabalho nas atividades de serviços pode ser de grande valia para a apreensão das novas configurações do trabalho nesse campo e, por consequência, da atividade do assistente social. Suas reflexões contribuem também para derrubar a ideia equivocada de que é apenas nas atividades industriais e no processo de produção de mercadorias que ocorre a intensificação do trabalho.

A pesquisa desenvolvida pelo autor em diferentes áreas do setor de serviços (bancos, telefonia, ensino privado, serviço público, entre outros) demonstra que a intensidade não se limita aos setores industriais, estendendo-se às diversas áreas do campo dos serviços, sejam públicos ou privados, sendo efeitos expansivos para todas as esferas da economia. Os dados levantados pela extensa investigação de 
Dal Rosso (2008) evidenciam a dinâmica de intensificação do trabalho assalariado no capitalismo contemporâneo, movimento que tem por base a adoção de diferentes mecanismos de superexploração do trabalho e extração da mais-valia.

Para este autor, com a ampliação do setor de serviços e o contingente cada vez mais numeroso de trabalhadores nessas atividades, é de se esperar que esteja em curso grande pressão por intensificação do trabalho, especialmente nos setores mais competitivos e que mais concentram capital, como é o caso de finanças, telefonia, comunicações, pesquisas, entre outros.

Mas isto ocorre também no caso dos serviços sociais, que se baseiam mais na inteligência, capacidade relacional e defesa de direitos, como são os serviços prestados por profissionais no campo das políticas sociais, entre eles os assistentes sociais. Neste âmbito, é a totalidade das capacidades humanas que são ativadas quando se fala em intensidade.

Também o caráter social do trabalho assentado nas relações de cooperação com o coletivo de trabalhadores e no aprendizado mútuo que daí deriva devem ser considerados na análise da intensificação do trabalho, resultando sempre em maior empenho, maior consumo de energia pessoal, maior dispêndio de capacidades físicas, cognitivas e emocionais que derivam em "mais trabalho".

A intensidade do trabalho para Dal Rosso (2008), diferentemente da produtividade do trabalho que decorre do desenvolvimento das forças produtivas, remete à maneira como é realizado $o$ ato de trabalhar, portanto a atenção está concentrada na pessoa do trabalhador, no coletivo de trabalhadores. Para ele, o que caracteriza a presença do fenômeno da intensificação do trabalho é o fato de ser exigido do trabalhador algo mais, um empenho maior, seja físico, intelectual ou emocional, ou alguma combinação dos três, o que é mais provável.

Em suas palavras:

A intensidade é, portanto, mais que esforço físico, pois envolve todas as capacidades do trabalhador, sejam as de seu corpo, a acuidade de sua mente, a afetividade despendida ou os saberes adquiridos através do tempo ou transmitidos pelo processo de socialização. Além do envolvimento pessoal, o trabalhador faz uso de relações estabelecidas com outros sujeitos trabalhadores, sem as quais o trabalho se tornaria inviável. (Dal Rosso, 2008, p. 21)

Sabemos que no capitalismo o controle sobre os meios e os processos de trabalho e, portanto, sobre a definição do grau de intensidade do trabalho, sai do controle 
do trabalhador e se concentra, total ou parcialmente, nas mãos do empregador, dadas as relações de compra e venda do trabalho assalariado mediadas pelo contrato.

Contudo, como o instrumento contratual não especifica o grau de intensidade do trabalho a priori, os trabalhadores podem resistir aos processos de intensificação mediante sua capacidade de organização e luta coletiva; e considerando também os padrões de intensidade construídos através do tempo e assumidos como referência pelos trabalhadores e suas organizações representativas para fundamentar sua pauta de reivindicações.

No entanto, é certo que nenhum desses argumentos pode conferir ao trabalhador o poder de controlar o grau de intensidade de sua atividade laboral, que em última análise expressa o grau de exploração a que é submetido pelo empregador em seu trabalho. Por essa razão a intensidade do trabalho permanece como objeto de permanente disputa, no âmbito do conflito social que opõe o interesse dos capitalistas, que exigem sempre "mais trabalho", e dos trabalhadores, que resistem e buscam ritmos e cargas de trabalho sempre menores (Idem, p. 25).

As conclusões da pesquisa de Dal Rosso (2008) apontam para a existência de "mais trabalho" nessa conjuntura de crise capitalista: o trabalho é mais intenso, o ritmo e a velocidade são maiores, o controle e a cobrança por resultados são mais fortes, bem como a exigência de polivalência, acúmulo de tarefas, versatilidade e flexibilidade. Intensificação do trabalho equivale pois ao aumento da degradação e da exploração do trabalho. Ou, em outros termos, a adoção de estratégias de redução do trabalho pago e ampliação do trabalho excedente, o que está na raiz do sofrimento do trabalhador assalariado.

As estratégias de intensificação do trabalho vão sendo incorporadas gradativa e sutilmente, e talvez não estejam ainda claramente perceptíveis para o conjunto de trabalhadores sociais, particularmente na esfera estatal. Mas ganham concretude no ritmo e na velocidade do trabalho, nas cobranças e exigências de produtividade, no maior volume de tarefas, nas características do trabalho intelectual demandado, no peso da responsabilidade (Idem, p. 188).

\section{Espaços ocupacionais e nova morfologia do trabalho do assistente social: expansão, intensificação e precarização}

Analisando as tendências do mercado de trabalho profissional, identificamos várias características de intensificação do trabalho apontadas por Dal Rosso. 
Uma ampla literatura nacional e internacional vem constatando o quanto as tecnologias de informação e comunicação intensificam os processos de trabalho, produzem um efeito controlador sobre dinâmicas e resultados, organizam e encadeiam as tarefas de modo que desapareçam a porosidade do trabalho e os tempos mortos, quantificam as tarefas realizadas e permitem a ampliação de mecanismos de fiscalização, controle e enquadramento do desempenho dos trabalhadores (Dal Rosso, 2008; Huws, 2009).

No caso do setor público-estatal, a exemplo do setor privado, significativas mudanças tecnológicas levam à incorporação da cultura do gerencialismo, que esvazia conteúdos reflexivos e criativos do trabalho, enquadrando processos e dinâmicas institucionais às metas de controle de qualidade e de produtividade a serem alcançadas.

A gestão do não trabalho vem mobilizando diferentes políticas sociais e profissionais, entre os quais o assistente social, chamado a participar, entre outros, de programas de geração de renda e inclusão produtiva, no âmbito das ações de "prontidão e educação para o trabalho", numa perspectiva que retrocede às origens da profissão quando o Serviço Social foi convocado a participar dos processos de disciplinarização das famílias operárias no contexto da constituição do capitalismo urbano-industrial no país.

Também é possível constatar o crescimento de um tipo de demanda dirigida aos assistentes sociais em diferentes áreas, que afasta o profissional do trabalho direto com a população, pois são atividades que envolvem relações interpessoais, exigem ações continuadas, acompanhamento próximo e sistemático, incluindo atividades em campo.

Tem sido reiterativo o discurso dos assistentes sociais que atuam no âmbito do Suas, do SUS e também em outras áreas profissionais, o envolvimento excessivo com o preenchimento de formulários e planilhas padronizadas numa tela de computador, a multiplicação das visitas domiciliares para fins de controle institucional das provisões e prestações sociais, a realização de cadastramentos da população que, quando assumidos de forma burocrática e repetitiva, não agregam conhecimento e reflexão crítica sobre a realidade dos usuários e seus territórios de vivência, rebaixam a qualidade do trabalho técnico e impedem que profissionais especializados possam realizar o trabalho intelectual nuançado para o qual estão (ou deveriam estar) capacitados a produzir.

Trata-se de uma dinâmica institucional que vai transformando insidiosamente a própria natureza da profissão de Serviço Social, sua episteme de profissão de 
caráter interventivo e relacional, que trabalha com as expressões mais dramáticas da questão social que incidem na vida dos indivíduos e grupos das classes subalternas, fragilizando a ação direta com segmentos populares e o desenvolvimento de trabalho socioeducativo numa perspectiva emancipatória.

Por outro lado, o conjunto dos trabalhadores sociais, entre os quais o assistente social, é afetado pela insegurança do emprego, precárias e flexíveis formas de contratação com redução ou ausência de benefícios e direitos trabalhistas, intensificação do trabalho e das formas de controle, baixos salários, pressão pela produtividade e cumprimento de metas e resultados imediatos, ausência de horizontes profissionais de mais longo prazo, falta de perspectivas de progressão e ascensão na carreira, de políticas continuadas de capacitação profissional, entre outros.

No âmbito do Serviço Social, verifica-se a ampliação de formas de subcontratação de serviços individuais dos assistentes sociais por parte de empresas de serviços ou de assessoria (empresas do eu sozinho ou $P J s$ ), de falsas cooperativas de trabalhadores, na prestação de serviços a governos, especialmente subnacionais, e organizações não governamentais, acenando para o exercício profissional privado (autônomo), temporário, por projeto, por tarefa, em função das novas formas de gestão do trabalho.

Trata-se de transformações contemporâneas que moldam e redefinem competências e atribuições profissionais em função dos novos modelos e formatos que assumem os programas e serviços sociais. Esta dinâmica institucional desencadeia novas requisições ao trabalho social no âmbito das políticas sociais, mas também novas possibilidades de atuação, impulsionadas pelos Programas de Transferência de Renda (PTR), com grande destaque ao Programa Bolsa Família (PBF), que passam a ser intensificados nessa conjuntura, assumindo centralidade nas políticas públicas e requerendo o desempenho de novas tarefas e atribuições profissionais, que precisam ser redefinidas e requalificadas pelos trabalhadores, rompendo com a perspectiva de "gestão do não trabalho".

Ao mesmo tempo, assiste-se a importantes deslocamentos nas formas de gestão do trabalho e de prestação de serviços sociais, com a dinâmica de subcontratações de empresas gerenciadoras intermediadoras de serviços à população, a ampliação de mecanismos de terceirização e até mesmo quarteirização do trabalho profissional, especialmente no nível estadual e municipal.

Em alguns campos de atuação, como o da habitação social, a terceirização, uma das expressões concretas da precarização, vem se consolidando como modelo 
de produção e gestão em que os assistentes sociais e o trabalho social passam a ser contratados por meio de processos licitatórios de que participam escritórios e empresas gerenciadoras, sem que, no entanto, a administração pública consiga regular e manter o controle estratégico deste processo.

Pesquisa sobre consultoria empresarial na cidade de São Paulo realizada por Azevedo (2013), mapeou quatro consultorias, todas com grande presença de assistentes sociais em seus quadros, uma das quais chegando a ter 1.300 profissionais cadastrados nas áreas de Psicologia, Psiquiatria, Direito e Serviço Social, outra exclusiva para a área de Serviço Social, com proprietárias e diretoras assistentes sociais, e cerca de $75 \%$ do corpo profissional constituído por assistentes sociais. Sua pesquisa evidenciou ainda que, sob o pretexto da "consultoria externa", o que ocorre de fato é a terceirização camuflada do trabalho social que deveria ser executado pelos assistentes sociais contratados diretamente pelas empresas.

Na política de saúde, as fundações e as Organizações Sociais (OSs) vêm se generalizando como modelo de gestão do trabalho e de prestação dos serviços, apesar do forte movimento de resistência dos trabalhadores e das organizações da área.

No campo sociojurídico, assistentes sociais terceirizados como prestadores de serviços mediante recibo de firmas individuais (PJ), são contratados para realizar laudos e produzir relatórios, e até mesmo subcontratam outros assistentes sociais para a realização de algumas atividades, como as visitas domiciliares, configurando-se, portanto, a quarteirização dos vínculos trabalhistas.

Na política de assistência social, nos marcos da implantação do Sistema Único de Assistência Social - Suas, e dos Centros de Referência de Assistência Social - Cras e Centros de Referência Especializado de Assistência Social - Creas, estados e municípios se utilizam de variadas modalidades de terceirização, pela mediação de entidades privadas, ONGs ou "cooperativas" de trabalhadores para a contratação de profissionais na prestação de serviços socioassistenciais, sob o discurso de falta de recursos para a criação de cargos, mesmo que recente medida tomada pelo governo federal faculte o uso de recursos federais repassados "fundo a fundo" para a contratação de trabalhadores efetivos via concurso público.

Além da precarização dos vínculos de trabalho, da insegurança e desproteção dos trabalhadores, as consequências da terceirização do trabalho social são desastrosa, pois o que preside o trabalho não é a lógica pública, mas os contratos priva- 
dos, obscurecendo-se a responsabilidade do Estado perante seus cidadãos, comprimindo ainda mais as possibilidades de inscrever as ações públicas no campo do direito.

Como vemos, ao contrário do que se propaga e se acredita amplamente, no contexto das políticas neoconservadoras e neoliberais, não há nem redução do papel do Estado nem extinção das políticas sociais. O que vem ocorrendo na realidade é a ampliação do Estado em defesa dos interesses do capital em detrimento das necessidades do trabalho, concomitante à transformação dos objetivos, perfis, conteúdos, intencionalidades e alcance das políticas de proteção social, de seus programas e serviços.

As pesquisas que vêm sendo desenvolvidas sobre as tendências do mercado de trabalho do assistente social atestam o paradoxo da expansão de demandas profissionais no campo das políticas sociais e da proteção social e, ao mesmo tempo e no mesmo processo, o aprofundamento das diferentes formas de intensificação e precarização, aberta ou velada, das condições em que este trabalho se realiza, afetando, ainda que com intensidades variadas, o conjunto dos trabalhadores.

Os dados levantados pela pesquisa que desenvolvemos na PUC-SP, juntamente com a Ufal e a UFRJ, no âmbito do Procad-Casadinho (financiada pela Capes), demonstram para todas as regiões do país, ainda que com especificidades regionais, a expansão com precarização no mercado nacional de trabalho profissional, reproduzindo a tendência geral do mundo do trabalho para a "classe-que-vive-do trabalho", na expressão de Ricardo Antunes.

Segundo levantamentos realizados pela equipe da Ufal (Trindade et al., 2012), em pesquisas sobre mercado de trabalho do assistente social, os influxos das mudanças do trabalho profissional têm atingido a condição do assistente social como trabalhador assalariado: baixos salários, instabilidade no emprego, desemprego dos profissionais, desvio de função, repercussão negativa do trabalho sobre a saúde dos profissionais, insatisfatórias condições de trabalho, extensão da jornada de trabalho, multiplicidade de vínculos por parte dos profissionais, multiplicidade de relações de trabalho dos empregados (efetivos e terceirizados) da mesma equipe, grande mobilidade entre o local de moradia e o espaço de trabalho.

As pesquisas evidenciaram também as dificuldades para o ingresso do profissional recém-formado no mercado de trabalho, decorrente da falta de experiência comprovada, falta de oportunidade de novos empregos, falta de vagas, campo fechado/competitivo. 
No período de 2006 a 2011, os trabalhos analisados constataram no Sudeste e no Nordeste: prevalência de assistentes sociais nas políticas de saúde e de assistência social, enquanto a assistência social predomina nas demais regiões; grande concentração da atuação no âmbito público municipal (com exceção do Nordeste, em que prevalece o estadual); tendência à interiorização dos postos de trabalho; precarização das condições de trabalho, instabilidade e insegurança nos postos de trabalho, sobretudo em relação à forma de contratação dos profissionais via seleção e/ou indicação/convite; baixos salários, que levam a mais de um vínculo empregatício, principalmente nas regiões Norte e Nordeste.

Em relação às atribuições e ações profissionais, constatou-se: predominância de atribuições que viabilizam a relação individual do profissional com os usuários/famílias, ainda que mediante ações diferenciadas, como: acompanhamento social de usuários/famílias; visitas domiciliares; plantão social; orientação individualizada, entrevista social, acompanhamento de casos sociais; solicitação de exames; acompanhamento de internação ambulatorial; abordagem/acolhimento, busca por inserção em programas e acesso a benefícios, tanto da assistência social quanto da previdência; auxílio financeiro, encaminhamento de providências a indivíduos, grupos e à população; esclarecimento de direitos, benefícios e serviços sociais.

Destaca-se como uma questão a ser aprofundada por outras pesquisas a introdução do uso de novas tecnologias digitais no exercício profissional, configurando-se a "desterritorialização" do trabalho do assistente social, mantendo os profissionais conectados aos seus postos de trabalho por meio da internet e de celulares, rompendo-se a separação entre o tempo do trabalho e o tempo do não trabalho, assim como com os âmbitos privados e públicos na vida dos assistentes sociais.

Os resultados desses estudos evidenciam por inteiro a condição do assistente social como trabalhador assalariado que vende sua força de trabalho em troca de um salário, sofrendo os mesmos constrangimentos do conjunto da classe trabalhadora, num processo continuado de desvalorização e superexploração.

A tensão entre projeto profissional e condição de trabalhador assalariado do Estado e/ou de organizações privadas de diferentes naturezas, coloca a necessidade de apreender com maior profundidade os circuitos através dos quais essa força de trabalho participa dos processos de mercantilização e alienação a que estão sujeitos o conjunto dos trabalhadores assalariados. 


\section{Novas questões, novos desafios: como enfrentá-los?}

As reflexões aqui expostas pretendem servir de estímulo para as projeções coletivas de uma categoria profissional que vem construindo um projeto profissional com dimensão teleológica, enfrentando as contradições de um trabalho tensionado pelas lutas de hegemonia presentes na sociedade, que reduzem ou ampliam as margens de autonomia profissional.

A luta pela redução da jornada de trabalho para trinta horas foi um movimento político dos mais relevantes, considerando a tendência do capitalismo de buscar, por todos os meios, a extensão ilimitada da jornada de trabalho, transgredindo tanto limites morais quanto limites físicos e naturais do trabalhador.

Mesmo diante de uma conjuntura adversa à ampliação dos direitos, os assistentes sociais conseguiram uma significativa vitória com a aprovação da jornada de trinta horas de trabalho sem redução salarial.

É certamente o movimento coletivo mais importante desses últimos anos em defesa de direitos do assistente social como trabalhador assalariado, mas que, como era de esperar, está sendo objeto de desconstrução por parte dos empregadores, exigindo da categoria profissional e de suas entidades políticas a adoção de diferentes estratégias coletivas para fazer valer esse direito para todos(as) os(as) profissionais do país e lutando pela sua extensão a todos os trabalhadores brasileiros.

Mas outras pautas começam a ingressar com força na agenda profissional exigindo novas respostas cada vez mais qualificadas pela pesquisa e pelo debate coletivo. Entre elas, as relações entre trabalho e saúde, ou mais propriamente entre trabalho, desgaste mental e adoecimento, como expressões no corpo e na mente dos trabalhadores dos processos de precarização e intensificação a que estão submetidos no ambiente de trabalho. Trata-se de um tema que precisa ser mais conhecido e debatido, exigindo um amplo programa de pesquisa para dar conta da amplitude da temática e das diferentes dimensões envolvidas.

Como observa Alves (2013, p. 127), “o tema da saúde do trabalhador não é apenas mais um tema do mundo do trabalho. Na verdade, ele é o tema crucial que expõe - na medida em que construirmos ferramentas teórico-metodológicas efetivas - a miséria humana sob as condições da exploração do capital em sua etapa de crise estrutural". 
Os impactos do trabalho na saúde do trabalhador têm sido estudados em vários campos do conhecimento, inclusive pelo Serviço Social, mas ainda muito pouco se conhece sobre $\mathrm{o}$ adoecimento de assistentes sociais diante da exposição continuada às mais dramáticas expressões da questão social, lidando com a dura realidade enfrentada por homens e mulheres das classes subalternas na sociedade brasileira; e também diante da impotência, em muitos casos, frente à ausência de meios e recursos que possam efetivamente remover as causas estruturais que provocam a pobreza e a desigualdade social.

É sabido, contudo, que a intensificação e a elevação da carga de trabalho nos diferentes ramos de atividade e espaços sócio-ocupacionais dos assistentes sociais produzem efeitos sobre o corpo e a mente, podendo resultar, conforme muitos analistas, em um novo padrão de problemas saúde-trabalho decorrentes das novas exigências do trabalho contemporâneo.

Para Alves (2013, p. 128):

Uma das principais manifestações da precarização do trabalho no capitalismo global é o adoecimento da subjetividade do trabalho vivo sob as condições da ordem salarial. Muitas vezes quando se trata do tema da precarização do trabalho no capitalismo se faz referência ao salário e emprego ou ainda às condições de trabalho etc. Entretanto, considero que a manifestação candente da precarização do trabalho em nossos dias ocorre através das ocorrências de adoecimentos e doenças do trabalho, expressão candente do esmagamento da subjetividade humana pelo capital, a negação do sujeito humano-genérico pelos constrangimentos da ordem burguesa.

No Serviço Social, tem sido cada vez mais comum testemunhar depoimentos dos assistentes sociais sobre situações de sofrimento e stress decorrentes da intensa pressão que sofrem no cotidiano das instituições e organizações, sobre assédio moral a que são submetidos por chefias e superiores hierárquicos, bem como referências ao esgotamento profissional e a quadros depressivos.

Torna-se urgente, pois, ampliar a pesquisa para diferentes realidades e espaços sócio-ocupacionais onde trabalham os assistentes sociais, mapear as situações concretas de sofrimento e desgaste físico e mental a que estão acometidos, tornar visíveis e socializar esse conhecimento nos diferentes momentos de encontro da categoria profissional, para extrair daí elementos que possam embasar as lutas por novas reivindicações e direitos que particularizem as específicas condições de trabalho do assistente social no conjunto da classe trabalhadora. 
O trabalho profissional na perspectiva do projeto ético-político exige um sujeito profissional qualificado capaz de realizar um trabalho complexo, social e coletivo, que tenha competência para propor, negociar com os empregadores privados ou públicos, defender projetos que ampliem direitos das classes subalternas, seu campo de trabalho e sua autonomia relativa, atribuições e prerrogativas profissionais.

Isto supõe muito mais do que apenas a realização de rotinas institucionais, cumprimento de tarefas burocráticas ou a simples reiteração do instituído.

Envolve o assistente social como intelectual capaz de realizar a apreensão crítica da realidade e do trabalho no contexto dos interesses sociais e da correlação de forças políticas que o tensionam; a construção de estratégias coletivas e de alianças políticas que possam reforçar direitos nas diferentes áreas de atuação (saúde, previdência, assistência social, habitação, sócio-jurídico, organizações empresariais, ONGs etc.), na perspectiva de ampliar o protagonismo das classes subalternas na esfera pública.

Exige, portanto, um conhecimento mais amplo sobre os processos de trabalho, os meios de que dispõem o profissional para realizar sua atividade, a matéria sobre a qual recai a sua intervenção, e também um conhecimento mais profundo sobre o sujeito vivo responsável por esse trabalho, que é o próprio profissional assistente social.

\section{Considerações finais}

As reflexões contidas neste texto estão longe de esgotar as questões complexas que atravessam as polêmicas sobre a crise contemporânea e seus desdobramentos no campo das políticas, programas e serviços de proteção social, com rebatimentos no trabalho profissional.

As análises aqui apresentadas expressam tendências mundiais que se observam nas políticas sociais, mas que precisam ser consideradas no campo das disputas entre projetos societários, travadas pelas classes sociais na luta pela apropriação da riqueza social e do fundo público.

As políticas sociais e o sistema de proteção brasileiro, no contexto da crise internacional, reproduzem em grande medida os traços regressivos das tendências assinaladas, entre as quais: predomínio de políticas focalizadas na extrema pobre- 
za em detrimento de políticas sociais universais; ênfase nas condicionalidades ou contrapartidas como mecanismo de controle seletivo do acesso a benefícios a que os usuários teriam direito; substituição de análises socioeconômicas dos determinantes da pobreza por argumentos morais com base em comportamentos desviantes como causadores da pobreza; culpabilização dos pobres pela sua situação de privação; revalorização da família como principal canal de absorção dos "novos riscos sociais".

$\mathrm{Na}$ conjuntura dos grandes desafios a serem enfrentados, reafirma-se, pois, a perspectiva de defesa da esfera pública das políticas sociais e da proteção social, contra a mercantilização e privatização dos serviços sociais públicos, pela universalização e democratização de direitos e acessos ao conjunto da população. Impõe-se também, a partir de múltiplos espaços e estratégias políticas, a ação coletiva contra o rebaixamento intelectual e a desqualificação do trabalho profissional, a denúncia da violação de direitos dos próprios assistentes sociais como trabalhadores no exercício de sua cidadania laboral, a resistência ao produtivismo institucional, a luta pela melhoria das condições de trabalho e o fortalecimento do compromisso do Serviço Social por uma sociedade emancipada.

Recebido em 25/7/2013 - Aprovado em 9/8/2013

\section{Referências bibliográficas}

ADELANTADO, José (Coord.). Cambios en el Estado del bienestar: politicas sociales y desigualdades en España. Barcelona: Icaria Editorial/Universitat Autónoma de Barcelona, 2000.

. Cambios cuantitativos y cualitativos en los Estados del bienestar. Recortes y cambio de paradigma. El caso de España (1990-2012). Grupo de investigación GEPS (Globalización, Educación y Política Social). Departament de Sociología (UAB). Barcelona, 2012. ; CALDERÓN, Eduardo. Globalización y estados de bienestar: respostas semejantes a problemas parecidos? Cuadernos de Relaciones Laborales, Barcelona, v. 23, n. 2, 2005.

ALVES, Giovanni. Dimensões da precarização: ensaios de sociologia do trabalho. Bauru: Canal 6 Editora/Projeto Editorial Praxis, 2013. 
ANTÓN, Antonio. Debates sobre las ideas de la izquierda. In: Reestructuración del Estado de Bienestar. Madri: Talasa, Rediciones, 2009.

ANTUNES, Ricardo. Os sentidos do trabalho: ensaio sobre a afirmação e negação do trabalho. São Paulo: Boitempo, 1999.

O caracol e sua concha: ensaios sobre a nova morfologia do trabalho. São Paulo: Boitempo, 2005.

Adeus ao trabalho? Ensaios sobre as metamorfoses e a centralidade do mundo do trabalho. 13. ed. rev. e atual. São Paulo: Cortez, 2008.

A nova morfologia do trabalho e suas principais tendências In:

(Org.).

Riqueza e miséria do trabalho no Brasil II. São Paulo: Boitempo, 2013.

AZEVEDO, Fernanda. Consultoria empresarial: o Serviço Social posto a prova. Dissertação (Mestrado, PEPG em Serviço Social), PUC-SP, São Paulo, 2013.

BECK, Ulrich. La política económica de la inseguridad. El País, Madri, p. 4, 27 maio 2012.

BRAGA, Ruy. A política do precariado: do populismo à hegemonia lulista. São Paulo: Boitempo, 2012.

BRAVERMAN, Harry. Trabalho e capital monopolista: a degradação do trabalho no século XX. Rio de Janeiro: Zahar, 1981.

CABRERO, Gregorio R. La reestructuración del Estado del bienestar em España y la estructura de la desigualdad. In: ADELANTADO, José (Coord.). Cambios en el Estado del bienestar: políticas sociales y desigualdades en España. Barcelona: Icaria Editorial, 2000.

CASTEL, Robert. As metamorfoses da questão social: uma crônica do salário. Petrópolis: Vozes, 1998.

CLAYTON, Richard; PONTUSSON, Jonas. El recorte del Estado de bienestar reconsiderado. Reducción de los derechos, reestructuración del sector público y tendencias desigualitarias en las sociedades capitalistas avanzadas. In: WORLD POLITICS 51. Tradução Josep Ventura. Revisión técnica de Eloisa del Pino y Cesar Colino, 1998.

DAL ROSSO, Sadi. Mais trabalho!: A intensificação do labor na sociedade contemporânea. São Paulo: Boitempo, 2008.

. Crise socioeconômica e intensificação do Trabalho. In: ANTUNES, Ricardo (Org.). Riqueza e miséria do trabalho no Brasil II. São Paulo: Boitempo, 2013.

DRUCK, Graça. Principais indicadores da precarização social do trabalho no Brasil. In: XIV CONGRESSO BRASILEIRO DE SOCIOLOGIA, 14., Rio de Janeiro, 28 a 31 de julho de 2009 (versão preliminar). Disponível em: <http://www.flexibilizacao.ufba.br/bancodados. asp>. Acesso em: 9 set. 2011. 
ESPING-ANDERSEN, Gosta. As três economias políticas do Welfare State. Lua Nova, São Paulo, n. 24, 1991.

HUWS, Úrsula. A construção de um cibertariado? Trabalho virtual num mundo real. In: ANTUNES, Ricardo; BRAGA, Ruy (Orgs.). Infoproletários: degradação real do trabalho virtual. São Paulo: Boitempo, 2009.

IAMAMOTO, Marilda V. Serviço Social em tempo de capital fetiche: capital financeiro, trabalho e questão social. São Paulo: Cortez, 2007.

JESSOP, Bob. Crisis del Estado de bienestar: hacia una nueva teoría del Estado y sus consecuencias sociales. Bogotá: Siglo del Hombre Editores/Universidad Nacional de Colombia, 1999.

LAVINAS, Lena. Na contramão dos direitos universais. Notas para reflexão. In: Plataforma Política Social. Agenda para o Desenvolvimento, Campinas, Cadernos Temáticos, n. 1. Disponível em: <http://www.politicasocial.net.br>. Acesso em: 18 abr. 2013.

LIMA, Carlos. Trabalho e política social no mundo do capital em crise. In: PEREIRA, Potyara A. P.; PEREIRA, Camila P. (Orgs.). Marxismo e política social. Brasília: Ícone, 2010.

MARX, Karl. O capital (crítica da economia política). São Paulo: Civilização Brasileira, 1968. Livro 1, v. 1.

MEIRELlES, Dilmara Silva. O conceito de serviço. Revista de Economia Política, São Paulo, v. 26, n. 1, p. 119-136, jan./mar. 2006. Disponível em: <http://www.scielo.br/pdf/rep/ v26n1/a07v26n1.pdf>. Acesso em: 15 abr. 2012.

MÉSZAROS, István. A crise estrutural do capital. São Paulo: Boitempo, 2009.

MOREL, Nathalie; PALME, Joakim; PALIER, Bruno (Eds.). Towards a social investment Welfare State?: ideas, policies and challenges. Bristol: The Policy Press, 2012.

MORENO, Luis. La Europa asocial: caminamos hacia un individualismo posesivo? Barcelona: Ediciones Península, 2012.

NETTO, José Paulo. Capitalismo monopolista e Serviço Social. São Paulo: Cortez, 2009.

NOGUERA, José A. La reestructuración de la politica social en España. In: ADELANTADO, José (Coord.). Cambios en el Estado del bienestar: politicas sociales y desigualdades en España. Barcelona: Icaria Editorial/Universitat Autónoma de Barcelona, 2000.

PIERSON, Paul. Sobrellevando la austeridad permanente. reestructuración del Estado de bienestar en las democracias desarrolladas. In: . The new politics of the Welfare State. Tradução Josep Ventura e revisão técnica de Eloisa del Pino e Cesar Colino. Oxford, Oxford University Press. 2001 (p. 410-456). 
PEREIRA, Potyara A. P. Política Social no pós-guerra: ascensão e declínio. Serviço Social \& Saúde, Campinas, v. n. 10, dez. 2010.

RAICHELIS, Raquel. O trabalho do assistente social na esfera estatal. In: CFESS/ABEPSS (Orgs.). Direitos sociais e competências profissionais. Brasília: CFESS/Abepss, 2009.

. Intervenção profissional do assistente social e condições de trabalho no Suas. Serviço Social \& Sociedade, São Paulo, n. 104, especial, out./dez. 2010.

. O assistente social como trabalhador assalariado. Serviço Social e Sociedade, São Paulo, n. 107, jul./set. 2011.

O trabalho e os trabalhadores do Suas: o enfrentamento necessário na assistência social. In: Ministério Do Desenvolvimento Social. Gestão do Trabalho no âmbito do Suas: uma contribuição necessária para ressignificar as ofertas e consolidar o direito socioassistencial. Brasília: MDS, dez. 2011.

SCHÜTZ, Fernanda; MIOTO, Regina. C. T. O trabalho em serviços: contribuições para o debate do Serviço Social. Em Pauta, Rio de Janeiro, v. 10, n. 30, p. 61-82, $2^{\circ}$ sem. de 2012. TAYLOR-GOOBY, Peter. The New Welfare State Settlement in Europe. European Societies, v. 10, n. 1, p. 3-24, 2008.

TRINDADE, L. P. et al. Tendências do mercado de trabalho do Serviço Social apontadas pelas pesquisas publicadas no período 2006 a 2011. In: ENCONTRO NACIONAL DE PESQUISADORES EM SERVIÇO SOCIAL, 13., Juiz de Fora, 2012.

VIELLE, P.; POCHET, Ph.; CASSIERS, I. L'État social actif: vers un changement de paradigme? Bruxelles: PIE-Peter Lang, 2005.

YAZBEK, Maria Carmelita. Mudanças atuais no capitalismo, perspectivas para as políticas sociais e o Serviço Social. Palestra proferida no XIII Enpess. Juiz de Fora, 2012. (Mimeo.) 